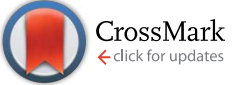

Cite this: Chem. Sci., 2015, 6, 7326

Received 18th August 2015

Accepted 23rd September 2015

DOI: $10.1039 / \mathrm{c} 5 \mathrm{sc} 03065 \mathrm{j}$

www.rsc.org/chemicalscience

\title{
Au'Cl-bound $\mathrm{N}$-heterocyclic carbene ligands form $\mathrm{M}_{4}^{\prime \prime}(\mathrm{LAuCl})_{6}$ integrally gilded cages $\uparrow$
}

\author{
William J. Ramsay, Jonathan A. Foster, Katharine L. Moore, Tanya K. Ronson, \\ Raphaël J. Mirgalet, David A. Jefferson and Jonathan R. Nitschke*
}

The incorporation of an $\mathrm{N}$-heterocyclic carbene $(\mathrm{NHC})$ moiety into a self-assembled $\mathrm{M}_{4}^{\prime \prime} \mathrm{L}_{6}$ cage framework required the $\mathrm{NHC}$ first to be metallated with gold(I). Bimetallic cages could then be constructed using zinc(॥) and cadmium(॥) templates, showing weak luminescence. The cages were destroyed by the addition of further gold(I) in the form of $\mathrm{Au}^{\prime}\left(2,4,6\right.$-trimethoxybenzonitrile) ${ }_{2} \mathrm{SbF}_{6}$, which caused the reversibly-formed cages to disassemble and controllably release the $\mathrm{Au}^{\prime}-\mathrm{NHC}$ subcomponent into solution. This release in turn induced the growth of gold nanoparticles. The rate of dianiline release could be tuned by capsule design or through the addition of chemical stimuli, with different release profiles giving rise to different nanoparticle morphologies.

\section{Introduction}

A variety of multitopic ligands have been designed to selfassemble with metal ions in order to construct three-dimensional metal-organic structures. ${ }^{1}$ Many of the novel applications of these supramolecular assemblies derive from the chemical functionalities of their incorporated ligands. ${ }^{2-13}$ As new rules are established to allow ligands incorporating more reactive groups to be built into supramolecular assemblies, new types of functionality can arise. ${ }^{\mathbf{1 4}}$

The shape and dimensions of discrete, self-assembled supramolecular structures are predominantly dictated by how ligands with a characteristic size and denticity come together in geometries defined by the coordination sphere of a given metal ion. ${ }^{15-28}$ The functionality ${ }^{29-36}$ of these assemblies can be shaped by incorporating ligands with active functional groups, which can also be modified in situ either pre- ${ }^{37-40}$ or post-synthetically. ${ }^{41-44}$ The response of a ligand to an external stimulus, such as light, can influence the guest binding affinity of the corresponding supramolecular structure. ${ }^{45}$ When a ligand contains a coordinated transition metal that is catalytically active, this active site can be orientated explicitly by the supramolecular framework, either protecting or exposing it; ${ }^{46}$ incorporating

Department of Chemistry, University of Cambridge, Lensfield Road, Cambridge CB2 1EW, UK. E-mail: jrn34@cam.ac.uk

$\dagger$ Electronic supplementary information (ESI) available: Experimental procedures, synthesis and characterization data for subcomponents and cages, and optical, microscopy, ESI-MS and NMR data. CCDC 1061936. For ESI and crystallographic data in CIF or other electronic format see DOI: 10.1039/c5sc03065j

\$ Current address: Department of Chemistry, University of Sheffield, Sheffield, S3 7HF, UK. more than one metal center thus can allow for division of labor between structural and functional metal centers.

$\mathrm{N}$-Heterocyclic carbenes (NHCs) are a useful class of electron-donating ligands that form strong metal-ligand bonds. ${ }^{47}$ Gold(I)-NHCs, in particular, have found applications in the fields of catalysis, ${ }^{48}$ pharmaceuticals, ${ }^{49}$ liquid crystals ${ }^{50}$ and optical devices. ${ }^{51,52}$ Despite the potential of incorporating metalbased NHC ligands into supramolecular constructs, opening new possibilities of control over their reactivity, few examples of self-assembled structures with this motif have been reported. ${ }^{53-56}$ We thus designed subcomponent $\mathbf{A}$ and its metallated carbene derivatives B-D (Scheme 1), to be capable of reversibly self-assembling with 2-formylpyridine and metal ions to form supramolecular structures, in order to probe the scope and limitations of the ability of this class of ligand to self-assemble

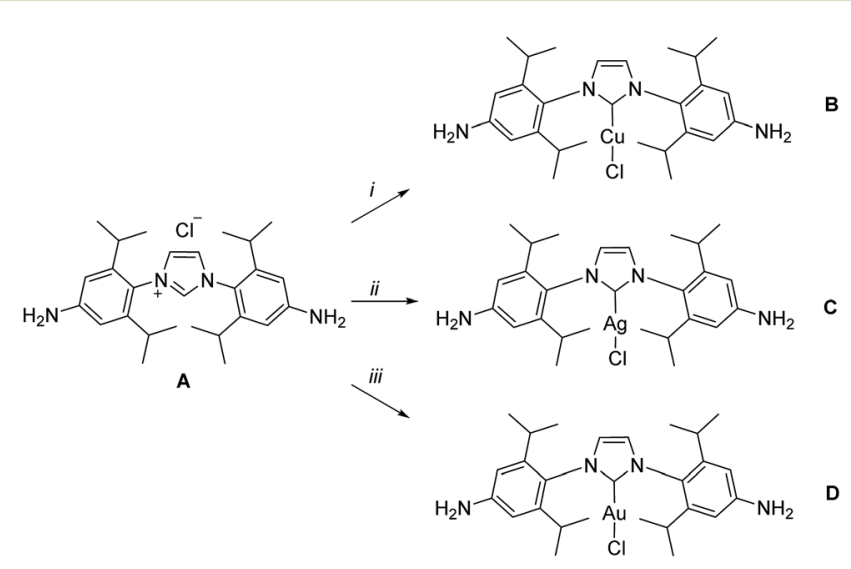

Scheme 1 Syntheses of subcomponents A-D. Reaction conditions: (i) $\mathrm{CuCl}, \mathrm{Na}_{2} \mathrm{CO}_{3}$, acetone, $60{ }^{\circ} \mathrm{C}, 16 \mathrm{~h}, 90 \%$; (ii) $\mathrm{Ag}_{2} \mathrm{O}, \mathrm{DCM}, 25^{\circ} \mathrm{C}, 2 \mathrm{~h}$, 90\%; (iii) $\mathrm{Au}$ (tht) $\mathrm{Cl}$, aq. $\mathrm{Na}_{2} \mathrm{CO}_{3}, \mathrm{DCM}, 25{ }^{\circ} \mathrm{C}, 0.5 \mathrm{~h}, 92 \%$. 
into supramolecular structures. $\mathrm{As} \mathrm{Au}^{\mathrm{I}}-\mathrm{NHC}$ complexes can be reduced to form carbene-stabilized gold nanoparticles (Au NPs), ${ }^{57}$ we anticipated that incorporating this ligand motif into a reversibly formed supramolecular structure could allow for new means to be developed to control the nucleation and growth conditions of Au NPs.

\section{Results and discussion}

\section{Subcomponent syntheses and cage preparation}

The syntheses of NHC dianilines A-D were accomplished as shown in Scheme 1. Imidazolium A was prepared through reduction of a bis-azido imidazolium precursor (Scheme S1†), prepared as described in the ESI. $\uparrow$ Taking advantage of the established ability of NHCs to coordinate to many metal ions, ${ }^{55}$ metallocarbenes B-D were prepared by metallating A following established, straightforward procedures. ${ }^{53,58,59}$

These subcomponents were subjected to conditions that were anticipated to lead to the preparation of self-assembled $\mathrm{M}_{4}^{\mathrm{II}} \mathrm{L}_{6}$ structures. ${ }^{25}$ Each was treated in turn with 2-formylpyridine and the prospective metal templates $\mathrm{Zn}^{\mathrm{II}}, \mathrm{Cd}^{\mathrm{II}}, \mathrm{Fe}^{\mathrm{II}}$ and $\mathrm{Co}^{\mathrm{II}}$. Although dianilines A-C did not yield discrete complexes with any of these templates, and $\mathbf{D}$ with $\mathrm{Fe}^{\mathrm{II}}$ or $\mathrm{Co}^{\mathrm{II}}$ gave intractable mixtures of products, $\mathbf{D}$ (6 equiv.) was observed to generate metal-organic cages $\mathbf{1}$ and $\mathbf{2}$ following treatment with 2 -formylpyridine (12 equiv.) and either zinc(II) or cadmium(II) di[bis(trifluoromethylsulfonyl)imide] (triflimide, $\mathrm{NTf}_{2}{ }^{-}$; 4 equiv.) respectively, as the uniquely observed products in solution (Fig. 1; ESI Sections 1.3 and $1.4 \dagger$ ). Confirmation of the $\mathrm{M}_{4}^{\mathrm{II}} \mathrm{L}_{6}$ stoichiometry was provided by electrospray ionization mass spectrometry (ESI MS; Fig. S10a and S20b $\dagger$ ), including high resolution MS (Fig. S10b and S20b广).

The observation that dianilines A-C did not lead to discrete cage formation suggested that a strong and inert metal-NHC bond was required in the ligand to construct a cage, which was provided by the gold(I) chloride moiety in D. Fluorescence spectroscopy for both 1 and $\mathbf{2}$ in dry acetonitrile (Fig. S11, S12, S21 and S22, $†$ respectively) indicated weak luminescence, with
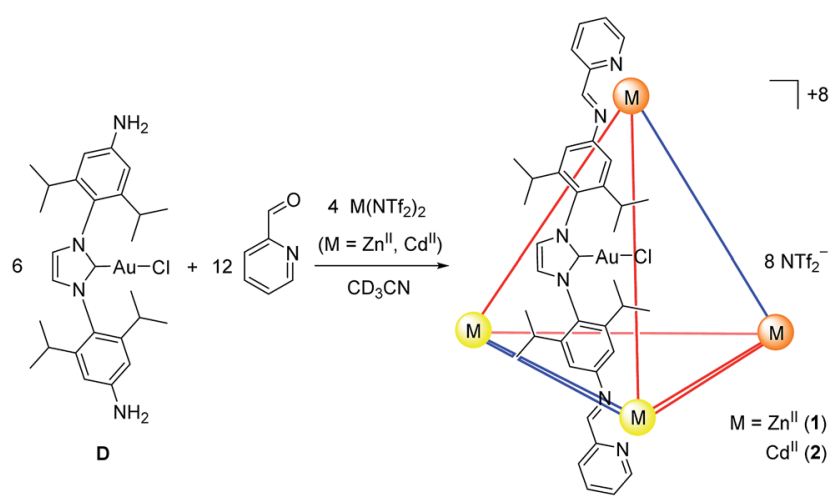

Fig. 1 Dianiline $D$ was the only dianiline observed to form $Z n_{4}^{\prime \prime} L_{6}(1)$ and $\mathrm{Cd}_{4}^{\prime \prime} \mathrm{L}_{6}$ (2) cages through subcomponent self-assembly. These cages are inferred to have approximate $S_{4}$ symmetry, consisting of two $\Delta$ (orange) and two $\Lambda$ (yellow) metal vertices and two anti (blue) and four syn ligands (red). Only one (syn) ligand is shown for clarity. bands that are attributed to both intra- and intermolecular $\mathrm{Au}^{\mathrm{I}} \cdots \mathrm{Au}^{\mathrm{I}}$ interactions, as observed in gold(I)-containing supramolecular architectures developed by Yam and co-workers. ${ }^{60}$ The removal of the gold-bound chloride from ligand $\mathbf{D}$ in cages 1 and 2 following the addition of chloride-binding metal cations, such as stoichiometric $\mathrm{Ag}^{\mathrm{I}}$ or excess $\mathrm{Zn}^{\mathrm{II}}$ or $\mathrm{Cd}^{\mathrm{II}}$ (Fig. S13, S14, S23 and S24†) caused disassembly, suggesting that coulombic repulsion between adjacent ligands destabilized the cage framework. Agents that engender the removal of chloride, therefore, provided a stimulus to trigger the response of cage destruction.

NMR spectra for the products 1 and 2 (Fig. S5 and S15, $\dagger$ respectively) yielded three imine signals. In the case of 2 , satellite signals associated with the imines were observed, attributed to $J$-coupling with the two spin-1/2 isotopes of cadmium. ${ }^{61}$ The three magnetically inequivalent ligand environments observed in both the ${ }^{1} \mathrm{H}$ and ${ }^{13} \mathrm{C}$ NMR spectra of the cages suggested that the achiral $S_{4}(\Lambda \Lambda \Delta \Delta)$ diastereomer of a $\mathrm{M}_{4} \mathrm{~L}_{6}$ framework was present in solution, but not the homochiral $T(\Delta \Delta \Delta \Delta / \Lambda \Lambda \Lambda \Lambda)$ or heterochrial $C_{3}(\Delta \Delta \Delta \Lambda / \Lambda \Lambda \Lambda \Delta)$ diastereomers. ${ }^{62,63}$ The steric bulk of the isopropyl groups is expected to hold the phenyl rings orthogonal to the central imidazolium ring; this coplanar orientation of the terminal phenylene rings has been shown to favor a syn arrangement of the ligands, ${ }^{64}$ making the $S_{4}$-symmetric framework the lowestenergy conformation, and thus the unique product observed in solution. Diffusion ordered spectroscopy (DOSY) was consistent in each case with all signals belonging to a single species (Fig. S9 and S19†). The ${ }^{19} \mathrm{~F}$ NMR signal for $\mathrm{NTf}_{2}{ }^{-}$was unchanged from its free value in cages $\mathbf{1}$ and 2 , consistent with the absence of anion encapsulation (Fig. S6 and S16 ).

In order to visualize the cage geometry, an energy-minimized model of 2 in the $S_{4}$ arrangement ${ }^{65}$ was constructed (Fig. 2b) based upon the X-ray crystal structure of $\mathbf{D}$ (Fig. 2a). The achiral framework is composed of two metal centers of the same handedness $(\Lambda)$ and two metal centers of opposite handedness $(\Delta)$. Each pair of metal centers of the same stereochemistry is connected by ligands adopting anti conformations (where the -AuCl moieties are directed to the outside of the cage), and the other four ligands are syn (where the $-\mathrm{AuCl}$ moieties are directed inwards); we acknowledge that other conformations may be possible in solution. Our model suggests that the cages are sufficiently flexible to allow the gold(I) centers to approach each other, accounting for the weak luminescence associated with the presence of gold-gold interactions (further modelling of the intermolecular cage interactions in 2 is provided in Fig. S22†).

\section{Nanoparticle synthesis}

Amines have been shown to reduce cationic gold species to $\mathrm{Au}^{0}$ and to cap the gold nanoparticles (Au NPs) formed following growth. ${ }^{67-70}$ Dianiline $\mathbf{D}$ thus possesses two useful characteristics in this context: it can reduce a gold source to $\mathrm{Au}^{0}$ (which can be stabilized by the oxidized aniline) and the NHC coordinated $\mathrm{Au}^{\mathrm{I}}$ can also participate in the formation of Au NPs, stabilized by the available carbene. The reduction of a soluble $\mathrm{Au}^{\mathrm{I}}$ source in 


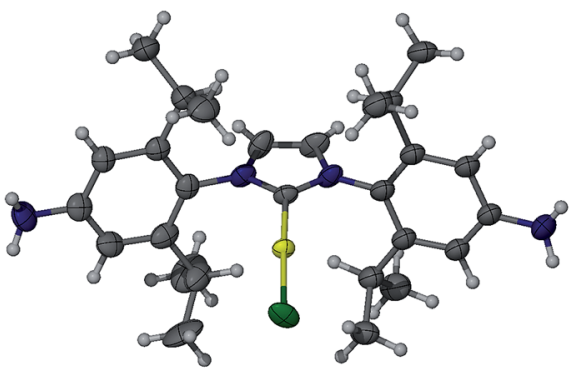

b
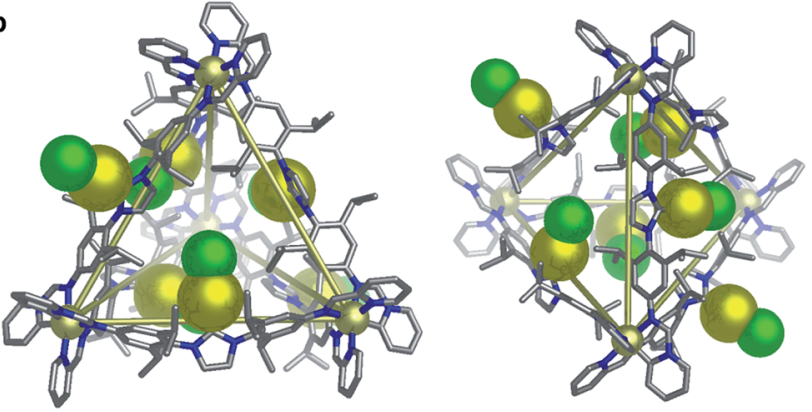

Fig. 2 (a) ORTEP representation of the crystal structure of $D$, showing thermal ellipsoids at $40 \%$ probability level. Solvent molecules and disorder are omitted for clarity. (b) Two views of a model of the MM2 (ref. 66) energy-minimized structure of 2 . The -AuCl units are shown in space-filling representation. Hydrogens and counterions are omitted for clarity (color scheme: carbon, grey; nitrogen, blue; cadmium, light yellow; gold, dark yellow; chloride, green)

acetonitrile $\left(\mathrm{Au}(\mathrm{tmbn})_{2} \mathrm{SbF}_{6} ; \mathrm{tmbn}=2,4,6\right.$-trimethoxybenzonitrile) for Au NP growth was thus investigated in two cases: with dianiline $\mathbf{D}$ alone, and when $\mathbf{D}$ was incorporated into cages $\mathbf{1}$ and 2.

Following the addition of $\mathrm{Au}(\mathrm{tmbn})_{2} \mathrm{SbF}_{6}$ (6 equiv.) to a solution of 1 in dry acetonitrile (ESI Section 3.1†), the surface plasmon resonance (SPR) band in the UV-Vis spectrum, attributable to $\mathrm{Au}$ NPs, ${ }^{71}$ was observed to grow in following a sigmoidal time course with steps corresponding to nucleation, growth, and

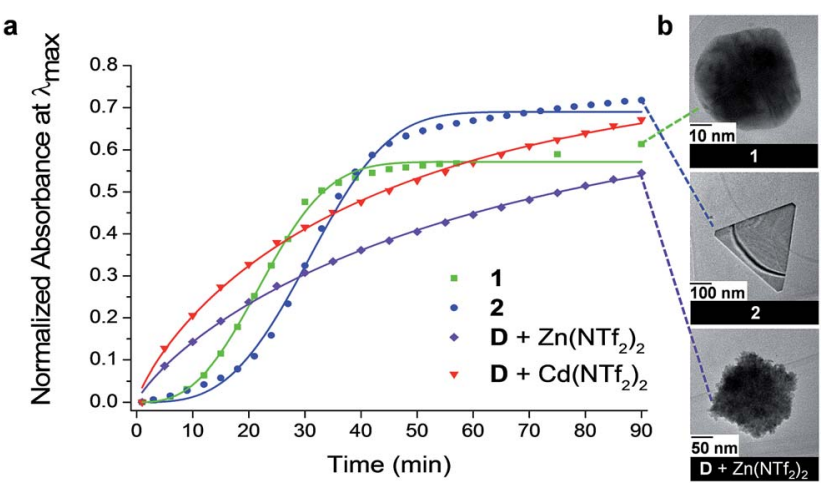

Fig. 3 (a) The evolution of the SPR UV-Vis band was monitored during Au NP formation when the reducing agent employed was provided by cages 1 and 2 and with $\mathrm{D}$ and either $\mathrm{Zn}\left(\mathrm{NTf}_{2}\right)_{2}$ or $\mathrm{Cd}\left(\mathrm{NTf}_{2}\right)_{2}$; the curves were fitted using the Avrami equation ${ }^{72,73}$ (ESI Section 3.6 $\dagger$ ). (b) Differences in Au NP morphology observed in the TEM images for growth conditions shown in (a). saturation (Fig. 3a); consistent growth features were observed in a second run (Fig. S26†). When cadmium-containing cage 2 was mixed with $\mathrm{Au}(\mathrm{tmbn})_{2} \mathrm{SbF}_{6}$ (6 equiv.) (ESI Section $3.2 \dagger$ ), the SPR band in the UV-Vis spectra began to grow in intensity approximately 22 min after mixing (Fig. 3a), a delay 10 min longer than was observed in the case of $\mathbf{1}$ (Fig. S36†). In both experiments, NP growth was observed only after part of the cage had first disassembled (Fig. S27, S28, S37 and S39†). When cage 1 decomposed to provide the reducing agent, TEM (Fig. S29†) and AFM (Fig. S30 $\dagger$ ) images displayed aggregates (250 $\mathrm{nm}$ in diameter) of approximately $5 \mathrm{~nm}$ Au NPs, together with Au NPs approximately $50 \mathrm{~nm}$ in diameter (Fig. 3b), following $90 \mathrm{~min}$ of NP growth. In contrast, when cage 2 disassembled $\{111\}$-faceted triangular prisms approximately $300 \mathrm{~nm}$ in edge length were observed (Fig. 3b), in addition to aggregates of $5 \mathrm{~nm}$ Au NPs (Fig. S40 and $\mathrm{S} 41 \dagger)$. Particle size distribution analysis of AFM measurements confirmed the presence of the larger triangular species alongside numerous small NP (Fig. S41d-h†); the triangular prisms constituted approximately $10 \%$ of the species counted, but approximately $52 \%$ of the total gold.

We also observed that when reagent grade acetonitrile $\left(0.01 \% \mathrm{H}_{2} \mathrm{O}\right)$ was used in place of the anhydrous solvent $\left(<0.001 \% \mathrm{H}_{2} \mathrm{O}\right)$ during the synthesis of Au NPs with cage $2,{ }^{74}$ the SPR band in the UV-Vis spectra appeared more rapidly (Fig. S42†). We infer that the higher water content of the solvent increased the rate of imine hydrolysis in 2 , resulting in a shortening of the nucleation stage. Instead of the triangular prisms observed with anhydrous solvent, TEM images revealed hexagonal plates (Fig. S42†) and aggregates of $5 \mathrm{~nm}$ particles. This difference in Au NP morphology may be attributed to the variation in the rate of cage breakdown.

Notably, control experiments involving equimolar quantities of $\mathbf{D}, \mathrm{Zn}\left(\mathrm{NTf}_{2}\right)_{2}$ or $\mathrm{Cd}\left(\mathrm{NTf}_{2}\right)_{2}$ and $\mathrm{Au}(\mathrm{tmbn})_{2} \mathrm{SbF}_{6}$ (ESI Sections 3.1.1 and 3.2.1†) resulted in a SPR band in the UV-Vis spectra immediately following mixing (Fig. 3a) and significantly different NP morphologies. When equimolar quantities of $\mathbf{D}$ and $\mathrm{Zn}\left(\mathrm{NTf}_{2}\right)_{2}$ were mixed with $\mathrm{Au}(\mathrm{tmbn})_{2} \mathrm{SbF}_{6}$, only aggregates were observed in the TEM images (Fig. 3b); nanoparticles greater than $5 \mathrm{~nm}$ in diameter were not observed in contrast to the case when 1 provided reductant $\mathbf{D}$ through its hydrolysis. In addition, none of the anisotropic Au NP morphologies grown starting from 2 were observed in the control experiment involving equimolar quantities of $\mathbf{D}, \mathrm{Cd}\left(\mathrm{NTf}_{2}\right)_{2}$ and $\mathrm{Au}(\mathrm{tmbn})_{2} \mathrm{SbF}_{6}$. Further control experiments in which only $\mathbf{A}$ or $\mathbf{D}$ were used in the reduction of $\mathrm{Au}^{\mathrm{I}}$ (ESI Sections 3.3 and $3.4, \dagger$ respectively) revealed similarly rapid rates of formation and small nanoparticle morphologies in the presence of either $\mathrm{Cd}^{\mathrm{II}}$ or $\mathrm{Zn}^{\mathrm{II}}$. Energy-dispersive X-ray spectroscopy (EDS) confirmed the presence of gold (with small quantities of nitrogen) across all experiments (Fig. S29, S32, S40 and S44†), with a higher organic content observed in the aggregates of smaller Au NPs compared to the larger anisotropic species; spectral features consistent with $\mathrm{Zn}$ or $\mathrm{Cd}$ were not observed, suggesting that these metals were not incorporated into the NPs. The aggregation of the Au NPs and the observation of organic material in the EDS spectra suggested that the oxidized bismonodentate ligand $\mathbf{D}$ may have acted to bridge between Au NPs, as has been observed with similar ligands. ${ }^{75}$ 
The kinetics of Au NP formation were assessed with the Avrami theoretical model for crystallization and growth ${ }^{72,73,76}$ (ESI Section 3.6†). In the Avrami equation, the overall kinetics are described by the apparent rate parameter $k_{\text {app }}$ which depends principally upon the nucleation rate - a slower $k_{\text {app }}$ is attributed to a lengthier nucleation stage. ${ }^{77}$ The $k_{\text {app }}$ of Au NP growth when 1 provided the reducing agent was $1.8 \times 10^{-4}$ (the units are $\min ^{-n}$ for all rate constants), with an Avrami exponent $(n)$ of 2.59; in a control experiment using $\mathbf{D}$ and $\mathrm{Zn}\left(\mathrm{NTf}_{2}\right)_{2}$ as reductant, the rate constant was $1.70 \times 10^{-2}$ with an exponent of 0.97. Similarly, Au NP growth where the reducing agent was provided by 2 displayed a rate constant of $1.5 \times 10^{-6}$ with an exponent of 3.4, and the control experiment using $\mathbf{D}$ and $\mathrm{Cd}\left(\mathrm{NTf}_{2}\right)_{2}$ gave a $k_{\text {app }}$ of $3.8 \times 10^{-2}$ with an exponent of 0.90 (Table S1 $\dagger$ ). As the Avrami exponent $n^{78-82}$ has been inferred to reflect the nucleation mechanism and directionality of growth, the constant nucleation rate $(n \approx 1)$ observed when $\mathbf{D}$ served as the reductant with different metal salts is consistent with the observation of spherical Au NPs. Similarly, the multi-dimensional growth $(n>1)$ observed when 1 or 2 were used as reductants is consistent with a heterogeneous nucleation mechanism being responsible for the anisotropic features. ${ }^{72}$ The rate constants and Avrami exponents observed when 1 and 2 were used as reductants suggest that the supramolecular structures impeded $\mathrm{Au}^{0}$ nucleation, in contrast to the faster nucleation observed when free $\mathbf{D}$ was present in solution.

Mechanistically, we infer that the addition of $\mathrm{Au}^{\mathrm{I}}$ to a solution of 1 or 2 first resulted in the abstraction of chloride, as noted above in the cases of other metal salts. This destabilizes the cage and results in its disassembly and release of free subcomponent $\mathbf{D}$. We attribute the difference in rate of dianiline release between $\mathbf{1}$ and $\mathbf{2}$ to the differences in thermodynamic stabilities between these two structures. The shorter nucleation stage provided by the breakdown of $\mathbf{1}$ in comparison to the longer nucleation stage provided by 2 is consistent with the labile $\mathrm{Zn}^{\mathrm{II}}$ centers that have faster ligand exchange kinetics $;^{83}$ it is this delay during the nucleation stage of Au NP growth that ultimately determines the final NP size and shape. The slow rate of $\mathbf{D}$ release from $\mathbf{1}$ and $\mathbf{2}$ thus brought about a longer nucleation stage and slower rate of $\mathrm{Au}^{\mathrm{I}}$ reduction, as required to produce thermodynamically-favored shapes with low-index facets, such as the $\{111\}$-faceted triangular prisms. ${ }^{\mathbf{8 4}}$ Several other factors, including the presence of small amounts of different salts (such as $\mathrm{ZnCl}_{2}$ or $\mathrm{CdCl}_{2}$ from cage decomposition, or the metal triflate salts) could also influence the final particle shape and kinetics of nanoparticle growth, ${ }^{\mathbf{8 4}}$ but the control experiments involving $\mathbf{D}$ and $\mathrm{Zn}^{\mathrm{II}}$ or $\mathrm{Cd}^{\mathrm{II}}$ were not consistent with this mechanism. The different growth rates and morphologies of the observed Au NPs were thus inferred to result from the incorporation of an $\mathrm{Au}^{\mathrm{I}}-\mathrm{NHC}$ dianiline ligand into the walls of metal-organic capsule as the diimine.

\section{Conclusions}

We have reported the synthesis of NHC-containing dianilines A-D, and demonstrated that subcomponent $\mathbf{D}$ alone was able to form supramolecular cages with zinc(II) and cadmium(II), thanks to the protection afforded to the reactive carbene center by the $\mathrm{Au}^{\mathrm{I}} \mathrm{Cl}$ moiety; we anticipate that similarly inert metalbound NHC complexes, such as Pt(II)-NHC, ${ }^{\mathbf{8 5}}$ could also be used to this effect. The removal of this gilding resulted in cage decomposition, which could be productively used in order to build up Au NPs of controllably variable morphologies. This supramolecular approach to modulating the rate of release of reducing agent affords a means of indirectly programming the morphology of Au NPs through reversible protection of the reducing amines within dynamic imine linkages. Our method circumvents the need to directly control the rate of reductant release, as is currently required in order to control Au NP morphology. ${ }^{84}$ The reagent release profile is governed by the thermodynamic stability of the supramolecular structure and can be purposely altered by adding chemical stimuli that disrupt cage stability. Although this method of control is prohibitively expensive, the controllable nonlinearity of response that we observed may be of interest in the context of signal transduction in complex chemical networks. ${ }^{86}$

\section{Acknowledgements}

This work was supported by the Marie Curie Academic-Industrial Initial Training Network on Dynamic Molecular Nanostructures (DYNAMOL) and the Engineering and Physical Sciences Research Council (EPSRC).

\section{Notes and references}

1 T. R. Cook and P. J. Stang, Chem. Rev., 2015, 115, 7001-7045.

2 J. M. Rivera, T. Martín and J. Rebek, Science, 1998, 279, 10211023.

3 T. Liu, Y. Liu, W. Xuan and Y. Cui, Angew. Chem., Int. Ed., 2010, 49, 4121-4124.

4 P. D. Frischmann, S. H. M. Mehr, B. O. Patrick, F. Lelj and M. J. MacLachlan, Inorg. Chem., 2012, 51, 3443-3453.

5 S. Mirtschin, A. Slabon-Turski, R. Scopelliti, A. H. Velders and K. Severin, J. Am. Chem. Soc., 2010, 132, 14004-14005.

6 M. M. J. Smulders, S. Zarra and J. R. Nitschke, J. Am. Chem. Soc., 2013, 135, 7039-7046.

7 J. S. Mugridge, G. Szigethy, R. G. Bergman and K. N. Raymond, J. Am. Chem. Soc., 2010, 132, 16256-16264.

8 R. Custelcean, P. V. Bonnesen, N. C. Duncan, X. Zhang, L. A. Watson, G. van Berkel, W. B. Parson and B. P. Hay, J. Am. Chem. Soc., 2012, 134, 8525-8534.

9 S. K. Samanta and M. Schmittel, Org. Biomol. Chem., 2013, 11, 3108-3115.

10 R. Frantz, C. S. Grange, N. K. Al-Rasbi, M. D. Ward and J. Lacour, Chem. Commun., 2007, 1459-1461.

11 S. Mecozzi and J. J. Rebek, Chem.-Eur. J., 1998, 4, 1016-1022. 12 G. Zhang, O. Presly, F. White, I. M. Oppel and M. Mastalerz, Angew. Chem., Int. Ed., 2014, 53, 5126-5130.

13 M. Han, J. Hey, W. Kawamura, D. Stalke, M. Shionoya and G. H. Clever, Inorg. Chem., 2012, 51, 9574-9576.

14 K. Liu, Y. Kang, Z. Wang and X. Zhang, Adv. Mater., 2013, 25, 5530-5548. 
15 B. Olenyuk, J. A. Whiteford, A. Fechtenkotter and P. J. Stang, Nature, 1999, 398, 796-799.

16 B. F. Abrahams, S. J. Egan and R. Robson, J. Am. Chem. Soc., 1999, 121, 3535-3536.

17 M. Eddaoudi, J. Kim, J. B. Wachter, H. K. Chae, M. O'Keeffe and O. M. Yaghi, J. Am. Chem. Soc., 2001, 123, 4368-4369.

18 H. Arora, J. Cano, F. Lloret and R. Mukherjee, Dalton Trans., 2011, 40, 10055-10062.

19 R. W. Saalfrank, A. Stark, K. Peters and H. G. von Schnering, Angew. Chem., Int. Ed. Engl., 1988, 27, 851-853.

20 N. Takeda, K. Umemoto, K. Yamaguchi and M. Fujita, Nature, 1999, 398, 794-796.

21 P. Mal, B. Breiner, K. Rissanen and J. R. Nitschke, Science, 2009, 324, 1697-1699.

22 H. T. Chifotides, I. D. Giles and K. R. Dunbar, J. Am. Chem. Soc., 2013, 135, 3039-3055.

23 M.-K. Chung, K. Severin, S. J. Lee, M. L. Waters and M. R. Gagne, Chem. Sci., 2011, 2, 744-747.

24 T. Weilandt, U. Kiehne, J. Bunzen, G. Schnakenburg and A. Lützen, Chem.-Eur. J., 2010, 16, 2418-2426.

25 T. K. Ronson, S. Zarra, S. P. Black and J. R. Nitschke, Chem. Commun., 2013, 49, 2476-2490.

26 J. Dömer, J. C. Slootweg, F. Hupka, K. Lammertsma and F. E. Hahn, Angew. Chem., 2010, 122, 6575-6578.

27 X.-P. Zhou, Y. Wu and D. Li, J. Am. Chem. Soc., 2013, 135, 16062-16065.

28 S. Pasquale, S. Sattin, E. C. Escudero-Adán, M. MartínezBelmonte and J. de Mendoza, Nat. Commun., 2012, 3, 785.

29 L. Isaacs, Acc. Chem. Res., 2014, 47, 2052-2062.

30 P. Ballester, Chem. Soc. Rev., 2010, 39, 3810-3830.

31 H.-J. Schneider and A. K. Yatsimirsky, Chem. Soc. Rev., 2008, 37, 263-277.

32 M. I. Sánchez, J. Mosquera, M. E. Vázquez and J. L. Mascareñas, Angew. Chem., Int. Ed., 2014, 53, 9917-9921.

33 S. J. Edwards, H. Valkenier, N. Busschaert, P. A. Gale and A. P. Davis, Angew. Chem., Int. Ed., 2015, 54, 4592-4596.

34 K. Yazaki, Y. Sei, M. Akita and M. Yoshizawa, Nat. Commun., 2014, 5, 5179.

35 J. Kang, J. Santamaría, G. Hilmersson and J. Rebek, J. Am. Chem. Soc., 1998, 120, 7389-7390.

36 D. J. Cram, M. E. Tanner and R. Thomas, Angew. Chem., Int. Ed. Engl., 1991, 30, 1024-1027.

37 L. M. Hancock, L. C. Gilday, S. Carvalho, P. J. Costa, V. Félix, C. J. Serpell, N. L. Kilah and P. D. Beer, Chem.-Eur. J., 2010, 16, 13082-13094.

38 G. Barin, M. Frasconi, S. M. Dyar, J. Iehl, O. Buyukcakir, A. A. Sarjeant, R. Carmieli, A. Coskun, M. R. Wasielewski and J. F. Stoddart, J. Am. Chem. Soc., 2013, 135, 2466-2469.

39 I. Pochorovski, M.-O. Ebert, J.-P. Gisselbrecht, C. Boudon, W. B. Schweizer and F. Diederich, J. Am. Chem. Soc., 2012, 134, 14702-14705.

40 Y. Li and A. H. Flood, Angew. Chem., Int. Ed., 2008, 47, 26492652.

41 K. K. Tanabe and S. M. Cohen, Chem. Soc. Rev., 2011, 40, 498-519.

42 P. L. Golas and K. Matyjaszewski, Chem. Soc. Rev., 2010, 39, 1338-1354.
43 D. Konkolewicz, A. Gray-Weale and S. Perrier, J. Am. Chem. Soc., 2009, 131, 18075-18077.

44 D. A. Roberts, A. M. Castilla, T. K. Ronson and J. R. Nitschke, J. Am. Chem. Soc., 2014, 136, 8201-8204.

45 M. Han, R. Michel, B. He, Y.-S. Chen, D. Stalke, M. John and G. H. Clever, Angew. Chem., Int. Ed., 2013, 52, 1319-1323.

46 H. J. Yoon, J. Kuwabara, J.-H. Kim and C. A. Mirkin, Science, 2010, 330, 66-69.

47 M. N. Hopkinson, C. Richter, M. Schedler and F. Glorius, Nature, 2014, 510, 485-496.

48 D. Gatineau, J.-P. Goddard, V. Mouriès-Mansuy and L. Fensterbank, Isr. J. Chem., 2013, 53, 892-900.

49 E. R. T. Tiekink, Crit. Rev. Oncol. Hematol., 2002, 42, 225248.

50 P. Espinet, Gold Bull., 1999, 32, 127-134.

51 R. Visbal, I. Ospino, J. M. López-de-Luzuriaga, A. Laguna and M. C. Gimeno, J. Am. Chem. Soc., 2013, 135, 4712-4715.

52 D. M. Roundhill and J. P. Fackler, Optoelectronic Properties of Inorganic Compounds, Springer, USA, 2013.

53 C. E. Willans, K. M. Anderson, P. C. Junk, L. J. Barbour and J. W. Steed, Chem. Commun., 2007, 3634-3636.

54 T. Fahlbusch, M. Frank, G. Maas and J. Schatz, Organometallics, 2009, 28, 6183-6193.

55 I. J. B. Lin and C. S. Vasam, Can. J. Chem., 2005, 83, 812-825. 56 C. Mejuto, G. Guisado-Barrios, D. Gusev and E. Peris, Chem. Commun., 2015, 51, 13914-13917.

57 J. Vignolle and T. D. Tilley, Chem. Commun., 2009, 72307232.

58 A. Hospital, C. Gibard, C. Gaulier, L. Nauton, V. Thery, M. ElGhozzi, D. Avignant, F. Cisnetti and A. Gautier, Dalton Trans., 2012, 41, 6803-6812.

59 O. Santoro, A. Collado, A. M. Z. Slawin, S. P. Nolan and C. S. J. Cazin, Chem. Commun., 2013, 49, 10483-10485.

60 X.-F. Jiang, F. K.-W. Hau, Q.-F. Sun, S.-Y. Yu and V. W.-W. Yam, J. Am. Chem. Soc., 2014, 136, 10921-10929.

61 W. Meng, T. K. Ronson and J. R. Nitschke, Proc. Natl. Acad. Sci. U. S. A., 2013, 110, 10531-10535.

62 A. M. Castilla, W. J. Ramsay and J. R. Nitschke, Acc. Chem. Res., 2014, 47, 2063-2073.

63 D. L. Caulder, C. Brückner, R. E. Powers, S. König, T. N. Parac, J. A. Leary and K. N. Raymond, J. Am. Chem. Soc., 2001, 123, 8923-8938.

64 W. Meng, J. K. Clegg, J. D. Thoburn and J. R. Nitschke, J. Am. Chem. Soc., 2011, 133, 13652-13660.

65 T. Beissel, R. E. Powers, T. N. Parac and K. N. Raymond, J. Am. Chem. Soc., 1999, 121, 4200-4206.

66 CAChe Workspace, WorkSystem Pro Version 7.5.0.85.

67 M. Aslam, L. Fu, M. Su, K. Vijayamohanan and V. P. Dravid, J. Mater. Chem., 2004, 14, 1795-1797.

68 S. Gomez, K. Philippot, V. Colliere, B. Chaudret, F. Senocq and P. Lecante, Chem. Commun., 2000, 1945-1946.

69 X. Lu, M. S. Yavuz, H.-Y. Tuan, B. A. Korgel and Y. Xia, J. Am. Chem. Soc., 2008, 130, 8900-8901.

70 C. Subramaniam, R. Tom and T. Pradeep, J. Nanopart. Res., 2005, 7, 209-217.

71 W. Haiss, N. T. K. Thanh, J. Aveyard and D. G. Fernig, Anal. Chem., 2007, 79, 4215-4221. 
72 Y. Zhou, W. Lin, F. Yang, W. Fang, J. Huang and Q. Li, Chem. Phys., 2014, 441, 23-29.

73 M. Avrami, J. Chem. Phys., 1940, 8, 212-224.

74 HPLC grade acetonitrile was purchased from Fisher Scientific with a $0.008 \%$ water content (max. 0.01\%). Anhydrous acetonitrile (99.8\%) was purchased from SigmaAldrich with a $<0.001 \%$ water content.

75 M. Orbach, M. Lahav, P. Milko, S. G. Wolf and M. E. van der Boom, Angew. Chem., Int. Ed., 2012, 51, 7142-7145.

76 P. N. Njoki, J. Luo, M. M. Kamundi, S. Lim and C.-J. Zhong, Langmuir, 2010, 26, 13622-13629.

77 M. L. Di Lorenzo and C. Silvestre, Prog. Polym. Sci., 1999, 24, 917-950.

78 A. T. W. Kempen, F. Sommer and E. J. Mittemeijer, J. Mater. Sci., 2002, 37, 1321-1332.
79 T. A. Baker, O. L. A. Monti and D. J. Nesbitt, J. Phys. Chem. C, 2011, 115, 9861-9870.

80 S. Ranganathan and M. von Heimendahl, J. Mater. Sci., 1981, 16, 2401-2404.

81 J. P. Gaviría, L. G. Navarro and A. E. Bohé, J. Phys. Chem. A, 2012, 116, 2062-2070.

82 G. Oyama, Y. Yamada, R.-I. Natsui, S.-I. Nishimura and A. Yamada, J. Phys. Chem. C, 2012, 116, 7306-7311.

83 I. A. Riddell, Y. R. Hristova, J. K. Clegg, C. S. Wood, B. Breiner and J. R. Nitschke, J. Am. Chem. Soc., 2013, 135, 2723-2733.

84 M. L. Personick and C. A. Mirkin, J. Am. Chem. Soc., 2013, 135, 18238-18247.

85 E. A. Baquero, J. C. Flores, J. Perles, P. Gómez-Sal and E. de Jesús, Organometallics, 2014, 33, 5470-5482.

86 D. Ray, J. T. Foy, R. P. Hughes and I. Aprahamian, Nat. Chem., 2012, 4, 757-762. 